\title{
SISTEMA DE CONTROLE DE TEMPERATURA DE ESBOÇO NA ENTRADA DO TREM ACABADOR*
}

Hormando Leocadio Júnior ${ }^{1}$ José de Pádua Ferreira²

\section{Resumo}

A otimização operacional no setor de desbaste da Linha de Tiras a Quente da Usiminas, Ipatinga, proporcionou redução do tempo de processamento dessa etapa, criando-se condições para aumento das temperaturas dos esboços na entrada do Trem Acabador (TA). Desse modo, para manutenção das temperaturas de acabamento dos laminados dentro da faixa de controle desejada, seriam necessárias menores velocidades de laminação no TA. Com a finalidade de garantir temperaturas desejadas na entrada do TA, que possibilitem adequadas velocidades, foi desenvolvido um sistema de controle de temperatura de esboço, que é acionado e desligado automaticamente na região inicial (topo), na extensão necessária do esboço. Esse sistema permitirá uma ampla exploração da nova condição de desbaste em menor tempo, com menor variabilidade da temperatura de entrada no TA, prevenindo ocorrências de estiramentos e de carepa, por temperatura alta nos topos e baixas nas bases dos laminados, maior uniformidade de propriedades mecânicas dos produtos, assim como aumento na capacidade produtiva.

Palavras-chave: Esboço; Trem acabador; Controle de temperatura.

\section{TRANSFER BAR TEMPERATURE CONTROL SYSTEM}

\begin{abstract}
The optimization at roughing sector in the Hot Strip Mill line at Usiminas Steel Plant, in Brazil, has provided reduction of processing time for this step, but it has created conditions for rising temperatures of the transfer bar at Finishing Mill (FM) entrance. Therefore, to maintain the transfer bar temperatures into the desired control range, lower rolling speed would be required. In order to ensure the desired temperature at the entrance of the FM, enabling appropriate speeds, a temperature control system has been developed. This system will allow an extensive exploration of the new condition of thinning in less time, with less variability in the inlet temperature of $F M$, preventing stretches and scales occurrence, high and low temperature on top and base of rolling product, greater uniformity of mechanical properties products, as well as an increase in productive capacity.
\end{abstract}

Keywords: Transfer bar; Finishing mill; Temperature control.

Engenheiro Mecânico, M.Sc., Pesquisa e Desenvolvimento, Usiminas Ipatinga, MG, Brasil.

Engenheiro Metalúrgico, M.Sc., Laminação a Quente, Usiminas Ipatinga, MG, Brasil.

* Contribuição técnica ao $51^{\circ}$ Seminário de Laminação - Processos e Produtos Laminados e Revestidos, 28 a 31 de outubro de 2014, Foz do Iguaçu, PR, Brasil. 


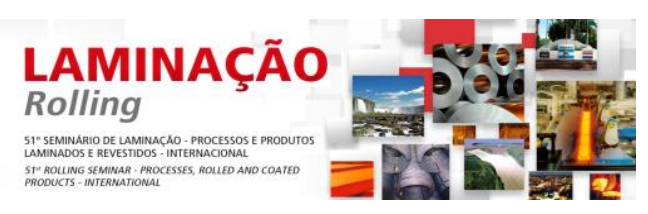

\section{INTRODUÇÃO}

A Linha de Tiras a Quente (LTQ) conta com fornos de aquecimento, dois laminadores desbastadores, R1 e R2, um Trem Acabador (TA) de seis cadeiras, um sistema misto (Tubo-U e Cortina) de resfriamento acelerado a fluxo d'água laminar e três bobinadeiras, sendo a temperatura do produto monitorada por pirômetros instalados ao longo da linha conforme mostrado na figura 1.

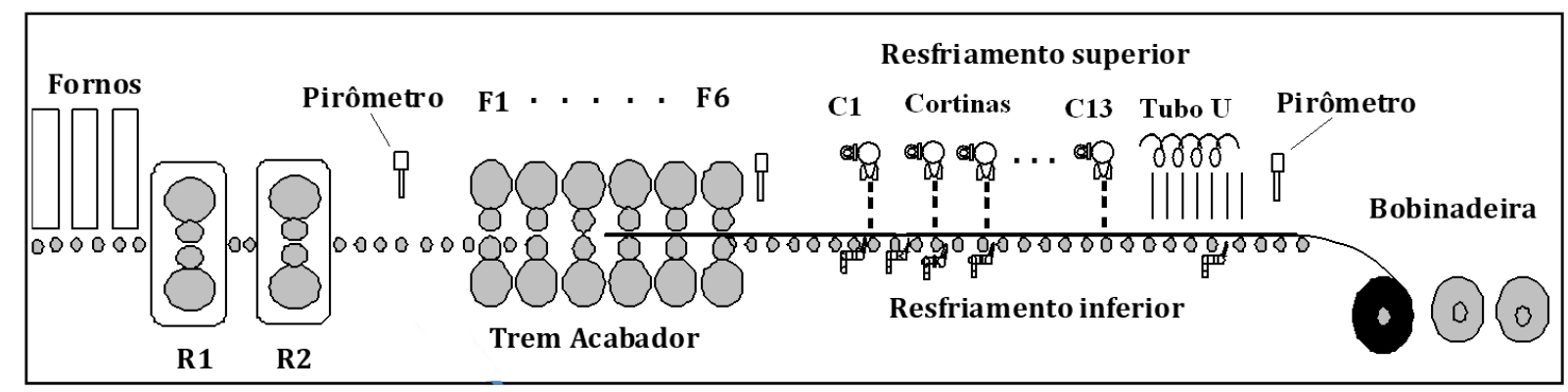

Figura 1. Esboço da linha de Laminação de Tiras a Quente da Usiminas.

Foi feita uma otimização no setor de desbaste que aumentou a frequência de ocorrências de esboços com temperaturas acima das especificadas para laminação, na entrada do Trem Acabador. Essa condição leva o Modelo de Controle do Trem Acabador (MCC) a definir uma redução na velocidade de laminação com o intuito de se obter a temperatura de acabamento de topo dentro da faixa de controle, com conseqüente perda de produtividade. Na condição de baixa velocidade o sistema de conservação de calor, mostrado na Figura 2, deveria evitar a ocorrência de temperaturas mais baixas na base. Porém, não tem mantido as temperaturas de entrada dentro das especificações, para tempos de laminação maiores. A ocorrência de temperaturas mais baixas na base, cria condições para geração de carepa, falta de uniformidade de propriedades e estiramento no TA.

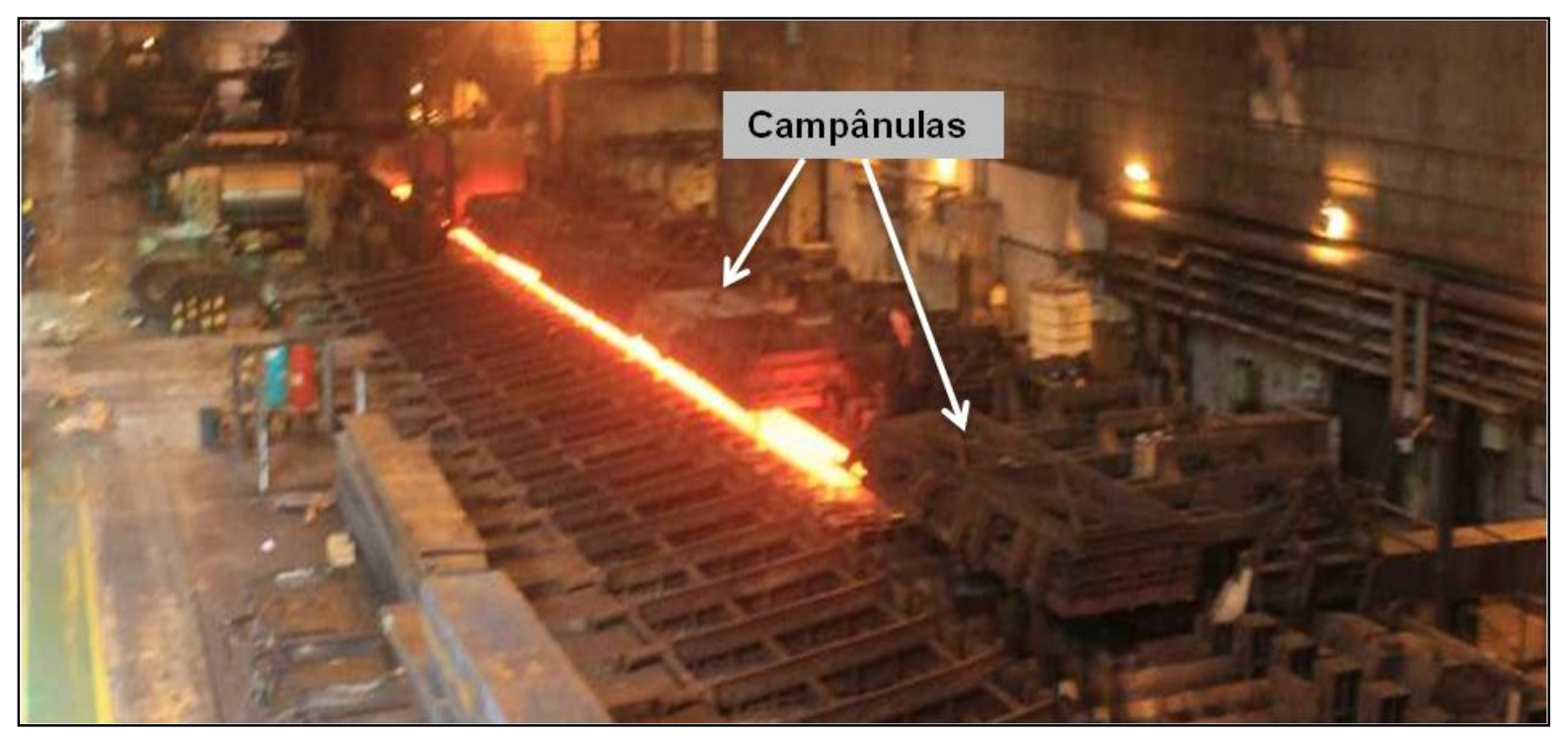

Figura 2. Fotografia do sistema de conservação de calor do LTQ.

* Contribuição técnica ao $51^{\circ}$ Seminário de Laminação - Processos e Produtos Laminados e Revestidos, 28 a 31 de outubro de 2014, Foz do Iguaçu, PR, Brasil. 


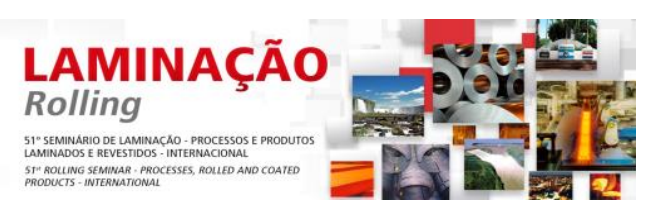

O Sistema de Conservação de Calor (SCC) está localizado entre o R2 e o Trem Acabador e utiliza campânulas móveis para reduzir a queda de temperatura do esboço.

Com a finalidade de garantir temperaturas desejadas na entrada do TA, que possibilitem adequadas velocidades, foi desenvolvido um sistema de controle de temperatura de esboço, que é acionado e desligado automaticamente. Esse sistema permitirá uma ampla exploração da nova condição de desbaste em menor tempo, com menor variabilidade da temperatura de entrada no TA, prevenindo ocorrências de estiramentos e de carepa por temperatura alta no topo e baixa na base do laminado, maior uniformidade de propriedades mecânicas dos produtos, assim como aumento na capacidade produtiva.

\section{MATERIAL E MÉTODO}

\subsection{Projeto do Controle de Temperatura de Esboço}

O projeto do Controle de Temperatura de Esboço (CTE) teve como requisito desenvolver um sistema de controle de temperatura capaz de promover um resfriamento uniforme e simétrico entre a superfície superior e inferior do esboço e possuir flexibilidade para ajustar a taxa de resfriamento durante o processo, utilizando jatos d'água incidentes como meio refrigerante, considerando: a) temperatura máxima de $1100^{\circ} \mathrm{C}$ e mínima de $1000^{\circ} \mathrm{C}$; b) taxa de resfriamento de 20 a $30^{\circ} \mathrm{C} / \mathrm{s}$; c) velocidade da mesa: 30 a $60 \mathrm{~m} / \mathrm{min}$; d) dimensões do esboço: 100 metros $\times 2$ metros $\times 30$ a 40 milímetros; e) comprimento máximo de resfriamento de 20 metros. A disponibilidade de água estava limitada a $13 \mathrm{~m} 3 / \mathrm{min}$ e o espaço disponível para montagem do CTE era de $3 \mathrm{~m}$, conforme mostrado na Figura 3.

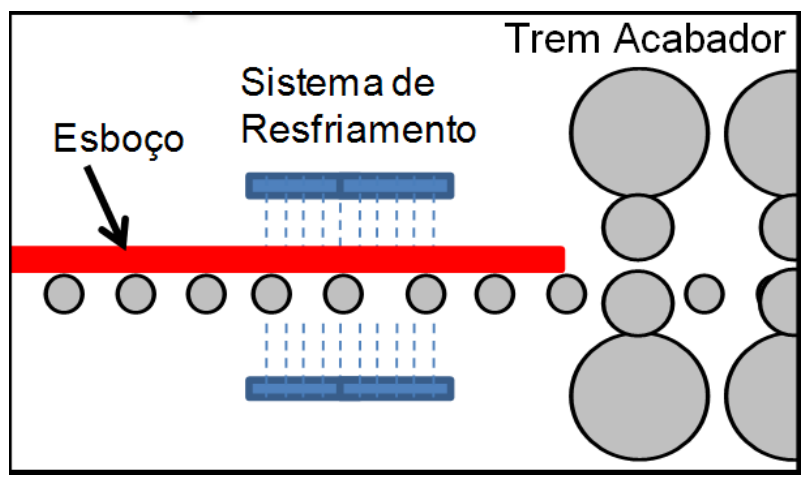

Figura 3. Localização do sistema de Controle de Temperatura de Esboço.

\subsection{Transferência de Calor e Hidrodinâmica em Jato Incidente}

Jatos d'água livres incidentes são utilizados como um eficiente meio de controle de resfriamento de tiras laminadas a quente, devido ao elevado fluxo de calor extraído com o uso de equipamentos relativamente simples [1]. Os sistemas mais comuns utilizam jato circular e planar (Cortina d'água), conforme mostrado na Figura 4. Por apresentarem menor custo de fabricação e manutenção, os jatos circulares (Tubo-U) foram escolhidos na confecção dos bancos de resfriamento. A transferência de calor e os fenômenos metalúrgicos, envolvidos no controle de resfriamento dos aços laminados a quente, são complexos [2-4]. Isto inclui condução de calor, convecção forçada monofásica, ebulição nucleada, filme de vapor, convecção natural para o

* Contribuição técnica ao $51^{\circ}$ Seminário de Laminação - Processos e Produtos Laminados e Revestidos, 28 a 31 de outubro de 2014, Foz do Iguaçu, PR, Brasil. 
ambiente, radiação e a geração de calor na mudança de fase do material, o que dificulta o acerto da temperatura final. Portanto, a determinação dos coeficientes de transferência de calor é fundamental para o controle da taxa de resfriamento e dimensionamento do sistema de resfriamento.
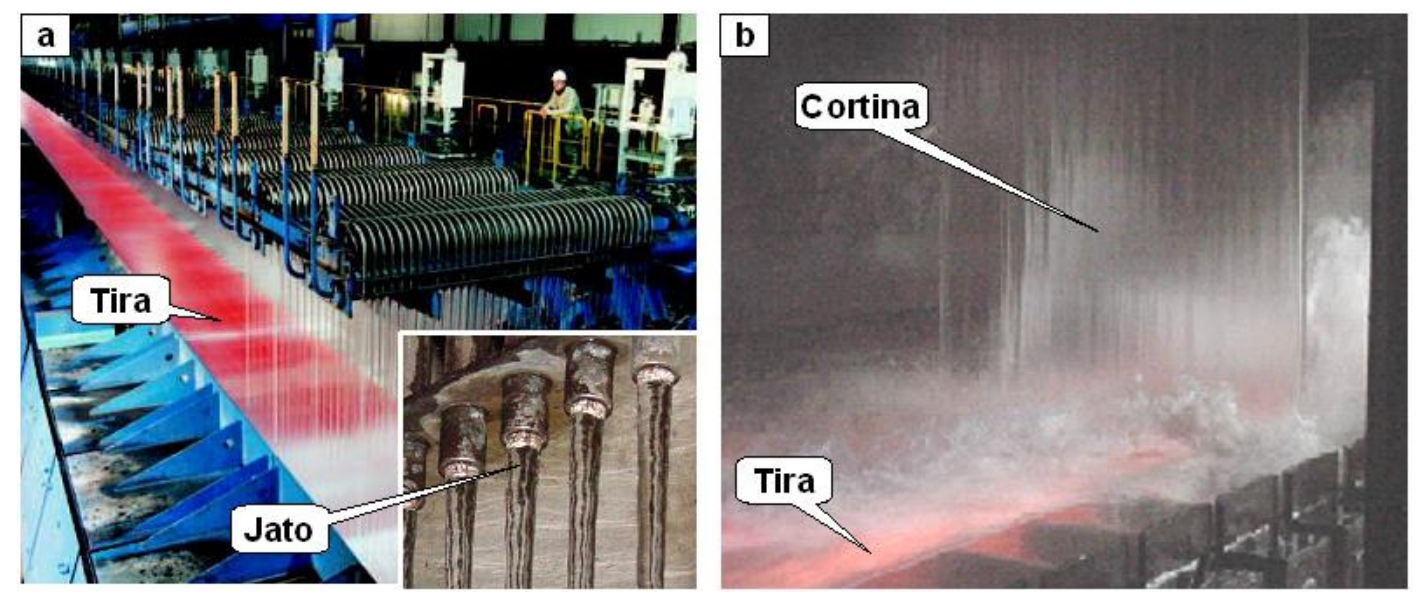

Figura 4. Sistemas de resfriamento de tira laminada a quente por fluxo laminar d'água: (a) Jato circular e (b) Cortina d'água [5].

A determinação dos parâmetros hidrodinâmicos do jato incidente, tais como velocidade e diâmetro, são importantes para o dimensionamento de um sistema de resfriamento. Uma maior eficiência térmica ocorre quando o jato atinge a superfície sem se romper, conforme mostrado na Figura 5a. Porém, o banco de resfriamento superior é instalado distante da mesa de rolos a fim de evitar acidentes durante a operação da LTQ e facilitar a manutenção, o que leva muitas vezes à ruptura do jato, conforme mostrado na Figura 5b. Os parâmetros que afetam o comprimento do jato são a tensão superficial $(\sigma)$, o Número de Reynolds $(\operatorname{Re})$, diâmetro do tubo $\left(D_{n}\right)$ e o Número de Weber (We) [6].

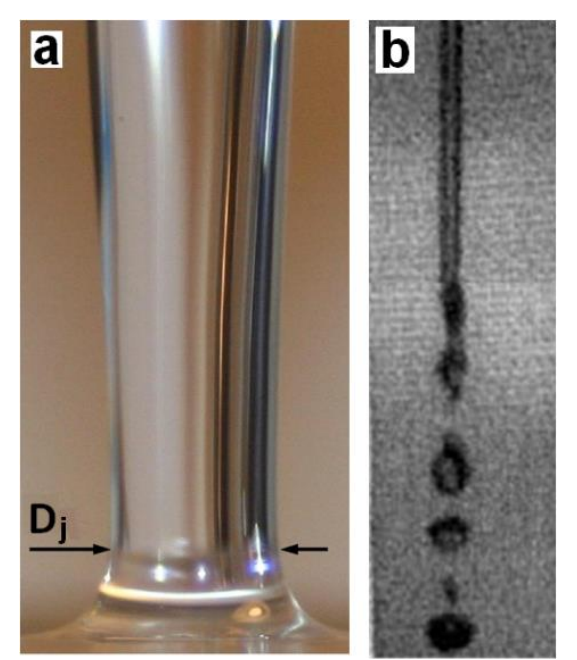

Figura 5. Fotografias de um jato d'água incidente (a)contínuo e (b) rompendo-se [5-6].

O diâmetro do jato incidente $\left(\mathrm{D}_{\mathrm{j}}\right)$ determina a área molhada, a qual é responsável por mais de $90 \%$ do calor retirado da superfície aquecida. O diâmetro do jato diminui à medida que ele se aproxima da superfície até atingir o seu menor valor em $D_{j}$, conforme mostrado na Figura 5a. O comprimento máximo de um jato d'água (L),

* Contribuição técnica ao $51^{\circ}$ Seminário de Laminação - Processos e Produtos Laminados e Revestidos, 28 a 31 de outubro de 2014, Foz do Iguaçu, PR, Brasil. 
antes que ocorra o seu rompimento, foi investigado por Sallam et al.[6] que sugerem a Equação 1 para o cálculo do comprimento L.

$$
\mathrm{L}=5 . \mathrm{We}^{0.5} \cdot \mathrm{D}_{\mathrm{n}}
$$

Os comprimentos $L$ calculados através da equação 1 foram de 622,960 e $1480 \mathrm{~mm}$, para os diâmetros de tubo de 9, 12 e $16 \mathrm{~mm}$, respectivamente. A fim de validar os valores calculados de $L$, foram realizados testes de bancada. $A$ velocidade da água na saída do tubo $\left(V_{n}\right)$ para os três diferentes diâmetros foi de $1,2 \mathrm{~m} / \mathrm{s}$ a $25^{\circ} \mathrm{C}$.

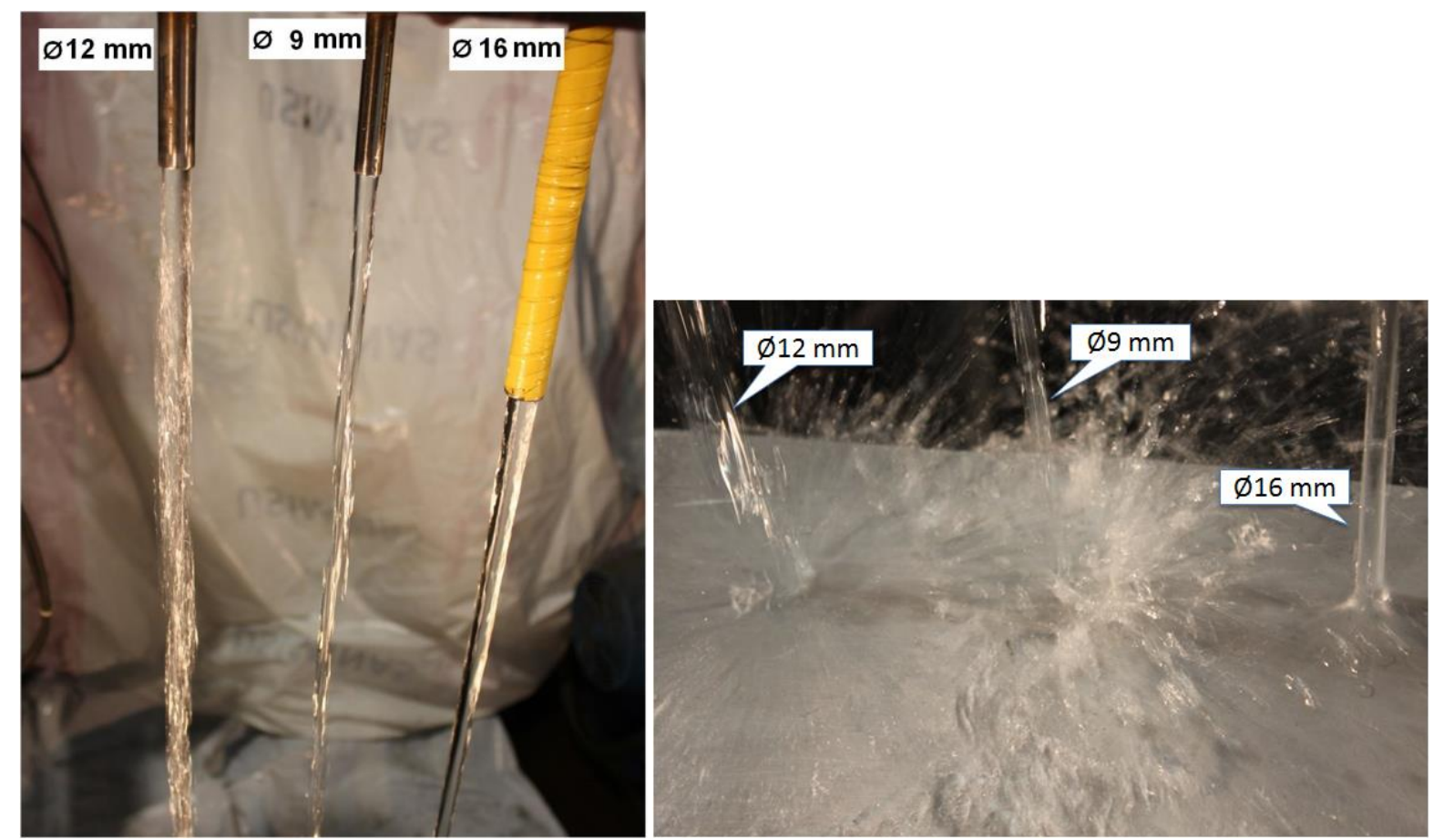

Figura 6. Comparação dos jatos gerados pelos tubos de 9, 12 e 16 mm de diâmetro.

Na Figura 6 é mostrada a comparação dos jatos gerados pelos tubos com diâmetros de 9, 12 e $16 \mathrm{~mm}$, sendo a figura da esquerda a de saída do tubo e a da direita a do jato ao atingir a superfície, onde somente o de $16 \mathrm{~mm}$ toca a superfície sem se romper com comprimento $L$ medido de $1730 \mathrm{~mm}$, ou seja, $250 \mathrm{~mm}$ maior que o calculado. Já o tubo de $12 \mathrm{~mm}$ produziu um comprimento estável de apenas $20 \mathrm{~mm}$, valor muito inferior ao calculado que foi de $960 \mathrm{~mm}$. O comprimento reto do tubo de $\varnothing 16 \mathrm{~mm}$ era de $120 \mathrm{~mm}$, enquanto o dos demais tubos era de $60 \mathrm{~mm}$. Os testes revelaram que o aumento do trecho reto e diâmetro aumentam a estabilidade e o comprimento máximo do jato. Conclui-se que o cálculo de $L$ não é somente função de We e de Re. Assim, a equação de Sallam et al. [6] deve ser reavaliada e usada com restrição. O tubo de $\varnothing 16 \mathrm{~mm}$ foi o escolhido para o projeto do banco de resfriamento Tubo-U, com trecho reto mínimo de $120 \mathrm{~mm}$.

\subsection{Fluxograma e Projeto dos Bancos de Resfriamento}

A Figura 7 mostra parcialmente o fluxograma de processo e instrumentação. 0 sistema possui três bancos de resfriamento superiores (Tubo-U) e três inferiores, ambos com jatos circular (1), sistema de medição de temperatura online por pirometria, antes e depois do sistema de resfriamento (2 e 3) e alimentação de água através do tanque elevado que abastece o resfriamento da Linha de Tiras a

* Contribuição técnica ao $51^{\circ}$ Seminário de Laminação - Processos e Produtos Laminados e Revestidos, 28 a 31 de outubro de 2014, Foz do Iguaçu, PR, Brasil. 


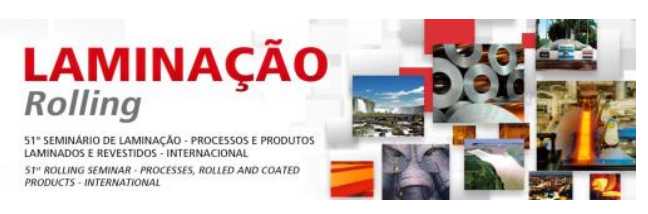

Quente (4). Cada banco de resfriamento possui um medidor de vazão eletromagnético, uma válvula controladora de vazão e uma válvula shut-off. Há dois sistema de remoção e contenção de água da superfície do esboço (blow-off), um antes e um depois do sistema de resfriamento, composto por três bicos spray pressurizados a 14 bar e vazão de $168 \mathrm{l} / \mathrm{min}$, de modo a evitar que a água retorne ao SCC e siga para o TA. O sistema foi limitado a três bancos devido ao espaço disponível. A válvula shut-off tem a função de fechamento rápido e estanque do banco de resfriamento. A válvula controladora de vazão possui a função de aumentar a flexibilidade no controle da taxa de resfriamento por banco durante o processamento do produto. Cada banco de resfriamento superior (BRS) e inferior (BRI) possui vazão máxima de 1100 e 1400 l/min, respectivamente.

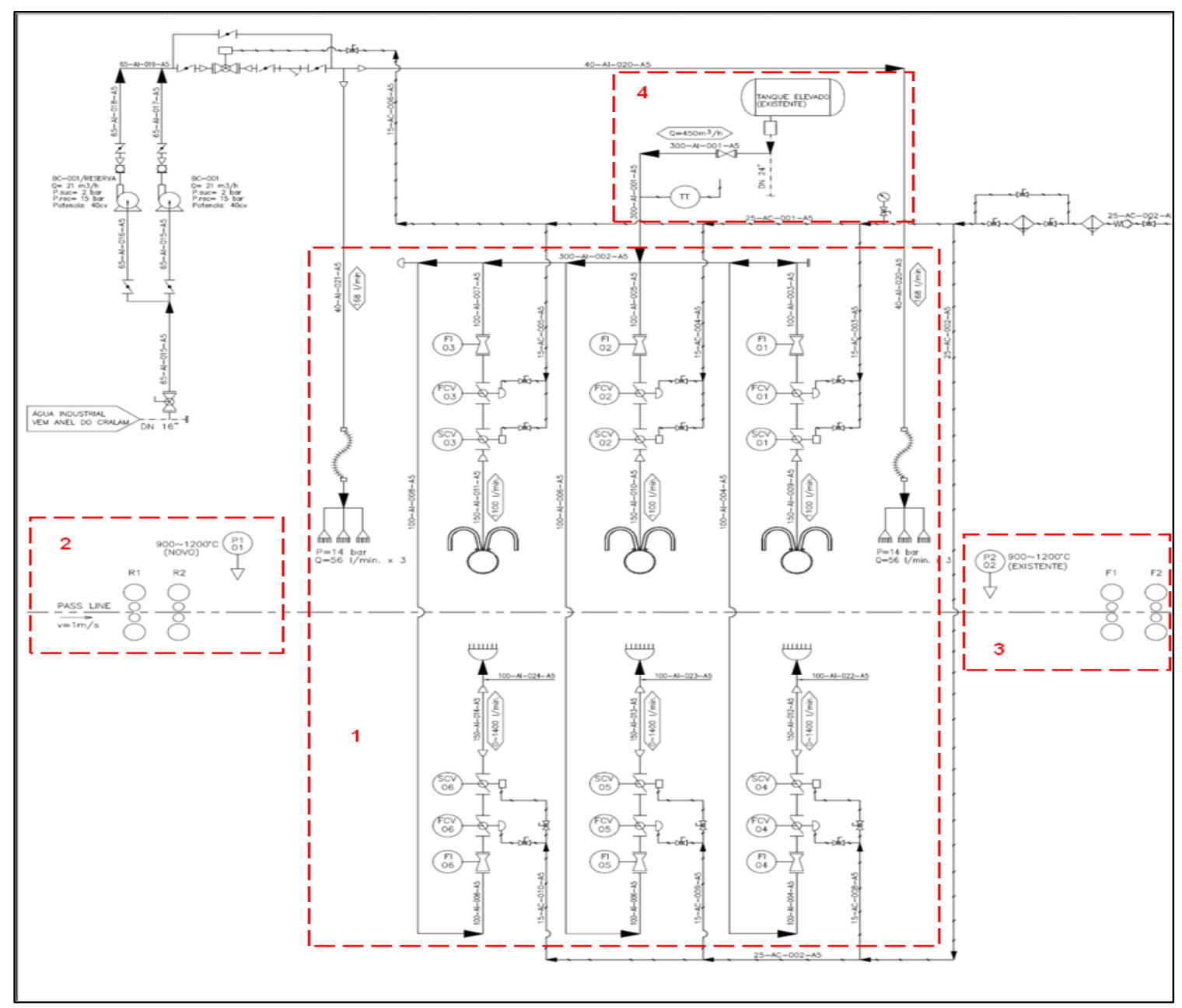

Figura 7. Vista parcial do fluxograma de processo e instrumentação do CTE.

A Figura 8 mostra o desenho do banco de resfriamento superior, Tubo-U, e inferior. No banco superior, os tubos foram montados alternadamente, porém formando uma cortina ao longo da largura do esboço. Possuem diâmetro interno de $16 \mathrm{~mm}$ e trecho reto de $135 \mathrm{~mm}$, maior do que o trecho reto de $120 \mathrm{~mm}$ utilizado nos testes de bancada (Figura 6), a fim de garantir que o jato d'água atinja a superfície do esboço sem se romper. O banco inferior é mostrado em perspectiva e em corte, onde é possível ver a inclinação dos bicos com o objetivo de aumentar a capacidade de resfriamento através do aumento da área molhada na parte inferior do esboço pois, conforme demonstrado por Leocadio et al.[5], a eficiência de resfriamento é menor

* Contribuição técnica ao $51^{\circ}$ Seminário de Laminação - Processos e Produtos Laminados e Revestidos, 28 a 31 de outubro de 2014, Foz do Iguaçu, PR, Brasil. 


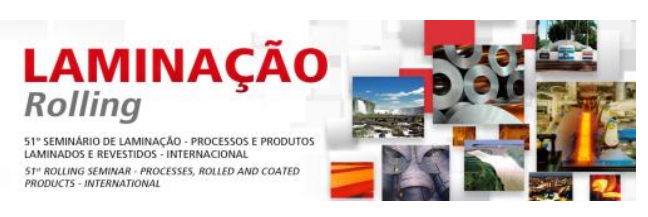

na superfície inferior do que na superior, para uma mesma vazão, pelo fato da água cair pela ação da gravidade.

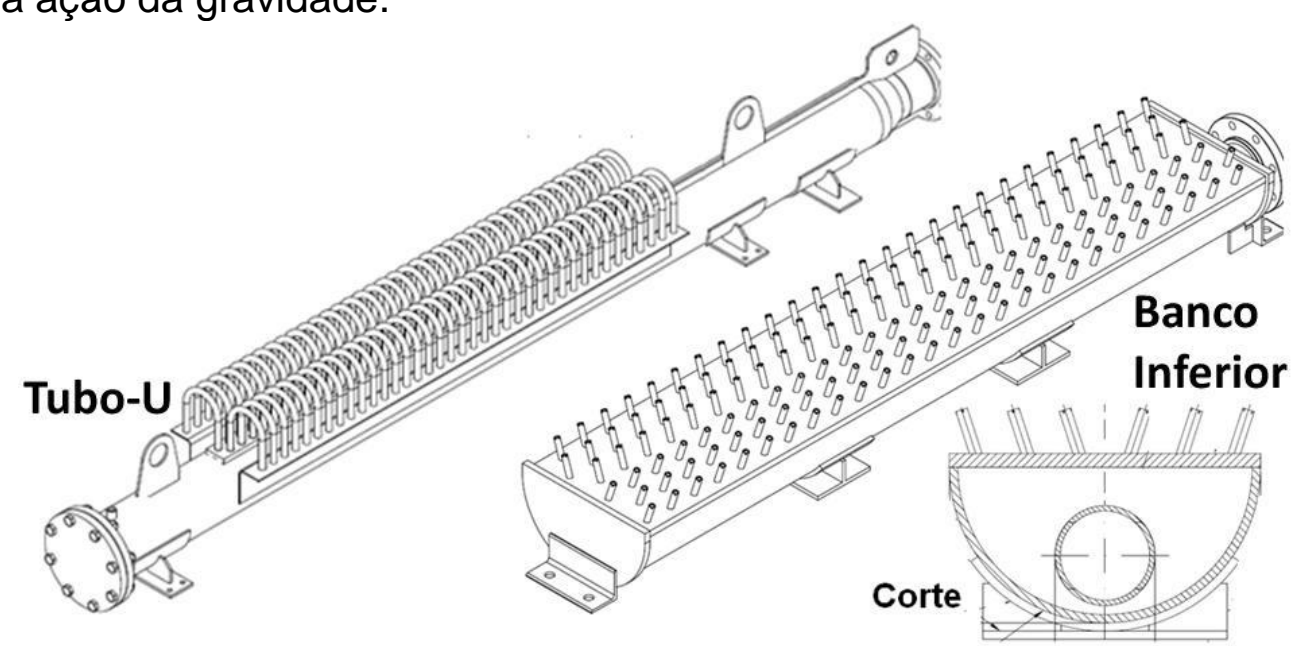

Figura 8. Desenho do banco de resfriamento superior e inferior.

\subsection{Levantamento da Taxa de Resfriamento}

A determinação dos coeficientes de transferência de calor é fundamental para o controle eficaz da temperatura do produto e dimensionamento de um sistema de resfriamento [5]. Com o objetivo de prever a capacidade de resfriamento do CTE e desenvolver um modelo de resfriamento online, o qual possa ser implementado na linha industrial, foram realizados testes de resfriamento em escala piloto simulando 0 CTE utilizando Resfriamento Acelerado Piloto (RAP), instalado no Centro Tecnológico da Usiminas [5], conforme mostra a Figura 9.

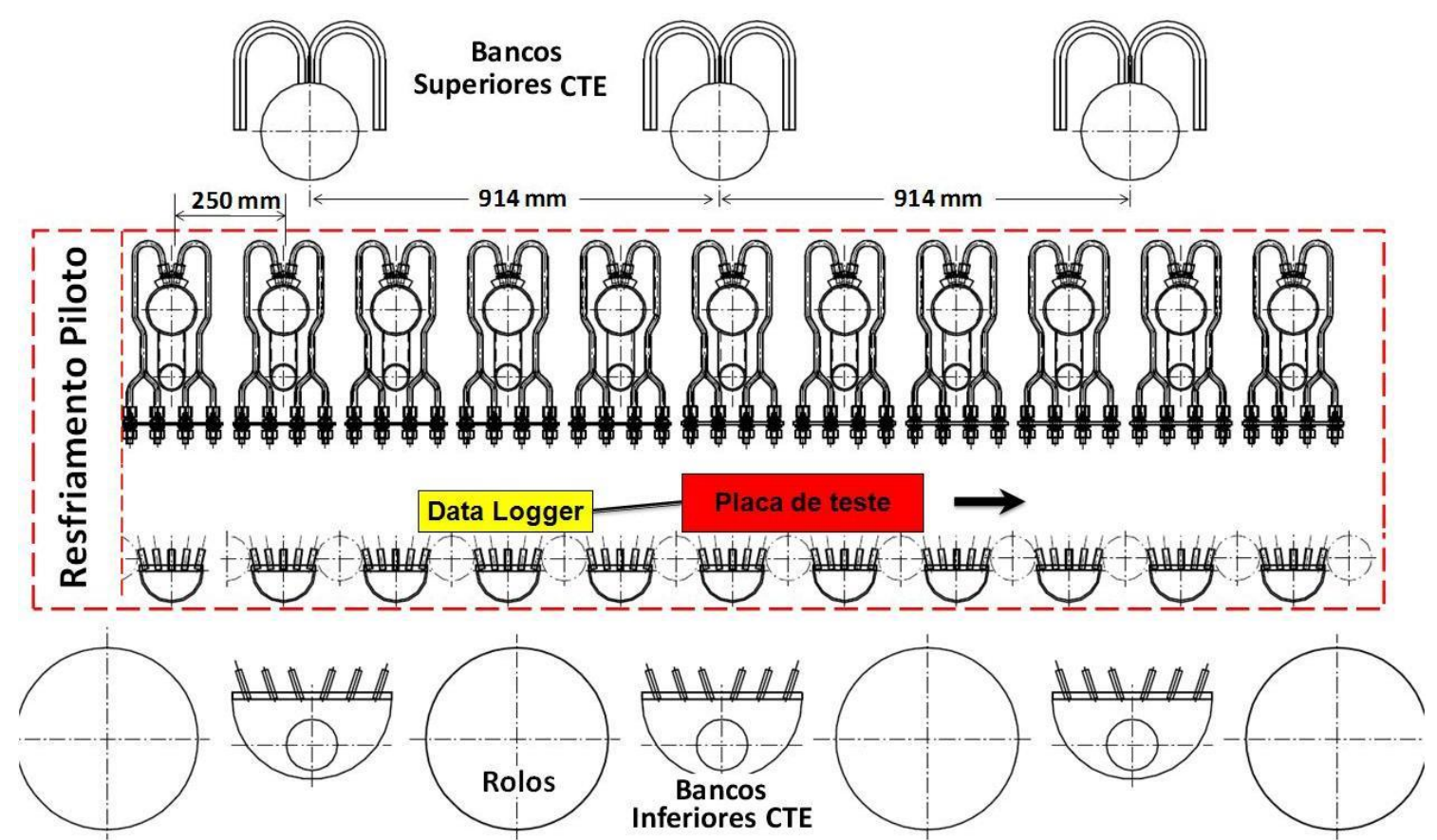

Figura 9. Esquema para a simulação do CTE no Resfriamento Acelerado Piloto.

No RAP foram estabelecidas condições hidrodinâmicas similares às esperadas no CTE, tais como vazão de água e distâncias de $914 \mathrm{~mm}$ entre os bancos de

* Contribuição técnica ao $51^{\circ}$ Seminário de Laminação - Processos e Produtos Laminados e Revestidos, 28 a 31 de outubro de 2014, Foz do Iguaçu, PR, Brasil. 


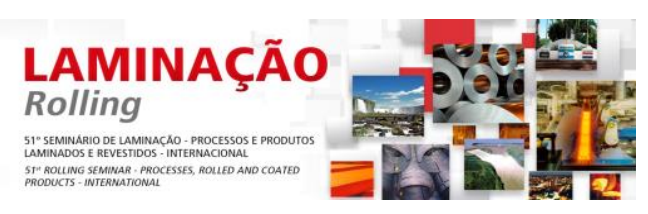

resfriamento, além da mesma área úmida de resfriamento, velocidade de impacto e temperatura do jato d'água incidente, uma vez que tais parâmetros afetam fortemente a transferência de calor em jatos incidentes em aço a alta temperatura $[4,5,7,8]$. Os testes consistiram em resfriar as placas de aço carbono de $40 \times 220 \times 550 \mathrm{~mm}$ aquecidas a $1150^{\circ} \mathrm{C}$ e instrumentadas interiormente com termopares tipo $\mathrm{K}$ de $\varnothing 1 \mathrm{~mm}$ instalados a 1,5, 3 e $10 \mathrm{~mm}$ da face superior e inferior (Figura 10). O sistema de aquisição de temperatura (data logger) estava acoplado à placa de teste, gerando o histórico de temperaturas a uma taxa de $100 \mathrm{~Hz}$. As velocidades da mesa no RAP foram de 30 a $60 \mathrm{~m} / \mathrm{min}$, iguais às especificadas no projeto do CTE. A placa foi aquecida até a temperatura de teste em um forno com capacidade de aquecimento máximo de $1300^{\circ} \mathrm{C}$.

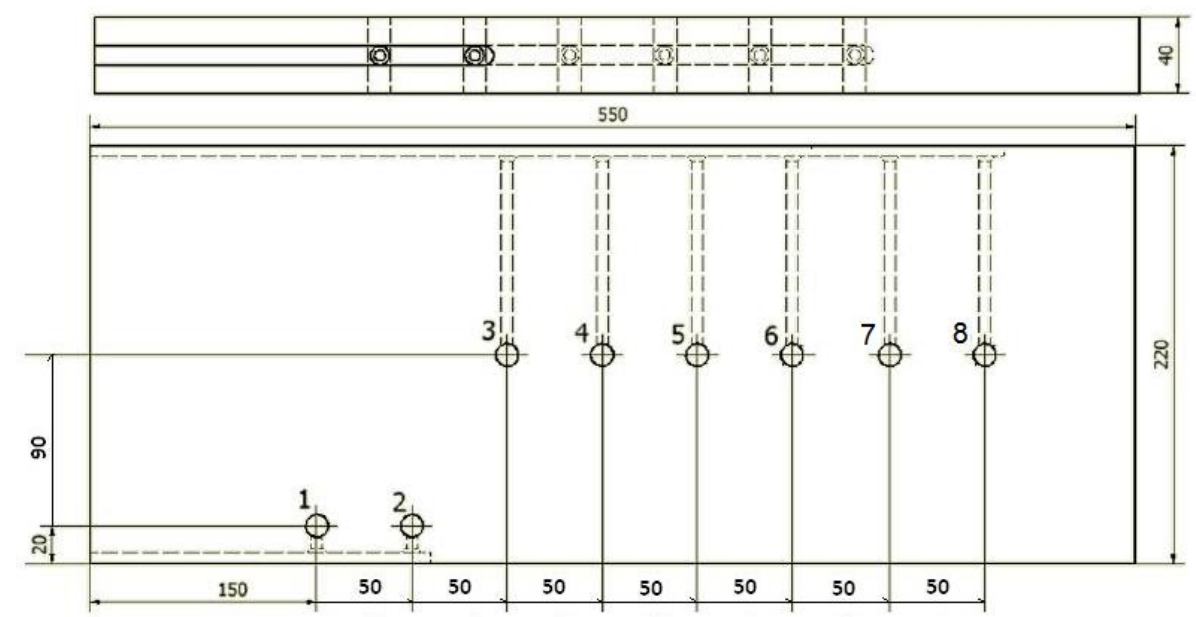

Figura 10. Posicionamento dos termopares na placa de teste.

Foi realizada uma análise numérica considerando as propriedades termofísicas do aço variando com a temperatura, utilizando o método inverso da condução de calor transiente $[9,10]$ a fim de se calcular as temperaturas e os fluxos de calor na superfície da placa a partir das temperaturas medidas internamente. Com as curvas de fluxo de calor obtém-se as correlações a serem usadas como condição de contorno no desenvolvimento do modelo matemático de resfriamento.

\section{RESULTADOS E DISCUSSÃO}

A Figura 11 mostra a vista lateral da instalação dos bancos de resfriamento com espaçamento de $914 \mathrm{~mm}$ devido à localização dos rolos existentes na linha. A distância entre a saída do tubo e a superfície do esboço é de $1400 \mathrm{~mm}$, a qual é menor que o valor encontrado de $1730 \mathrm{~mm}$ no teste de bancada (Figura 6), de modo a garantir um jato d'água contínuo até atingir a superfície do esboço.

A Figura 12a mostra a instalação do CTE na LTQ. Na Figura 12b é mostrado o sistema de elevação dos bancos superiores com o objetivo de permitir manutenção e retirada de sucata. O movimento ascendente dos bancos ocorre através do acionamento de um cilindro hidráulico. A Figura 12c mostra a cobertura realizada pelos três bicos spray (blow-off) ao longo da largura do esboço, com o objetivo de evitar que a água proveniente dos bancos de resfriamento superior avance ou retroaja na superfície do esboço, a fim de uniformizar a temperatura nas faces superior e inferior do esboço.

* Contribuição técnica ao $51^{\circ}$ Seminário de Laminação - Processos e Produtos Laminados e Revestidos, 28 a 31 de outubro de 2014, Foz do Iguaçu, PR, Brasil. 

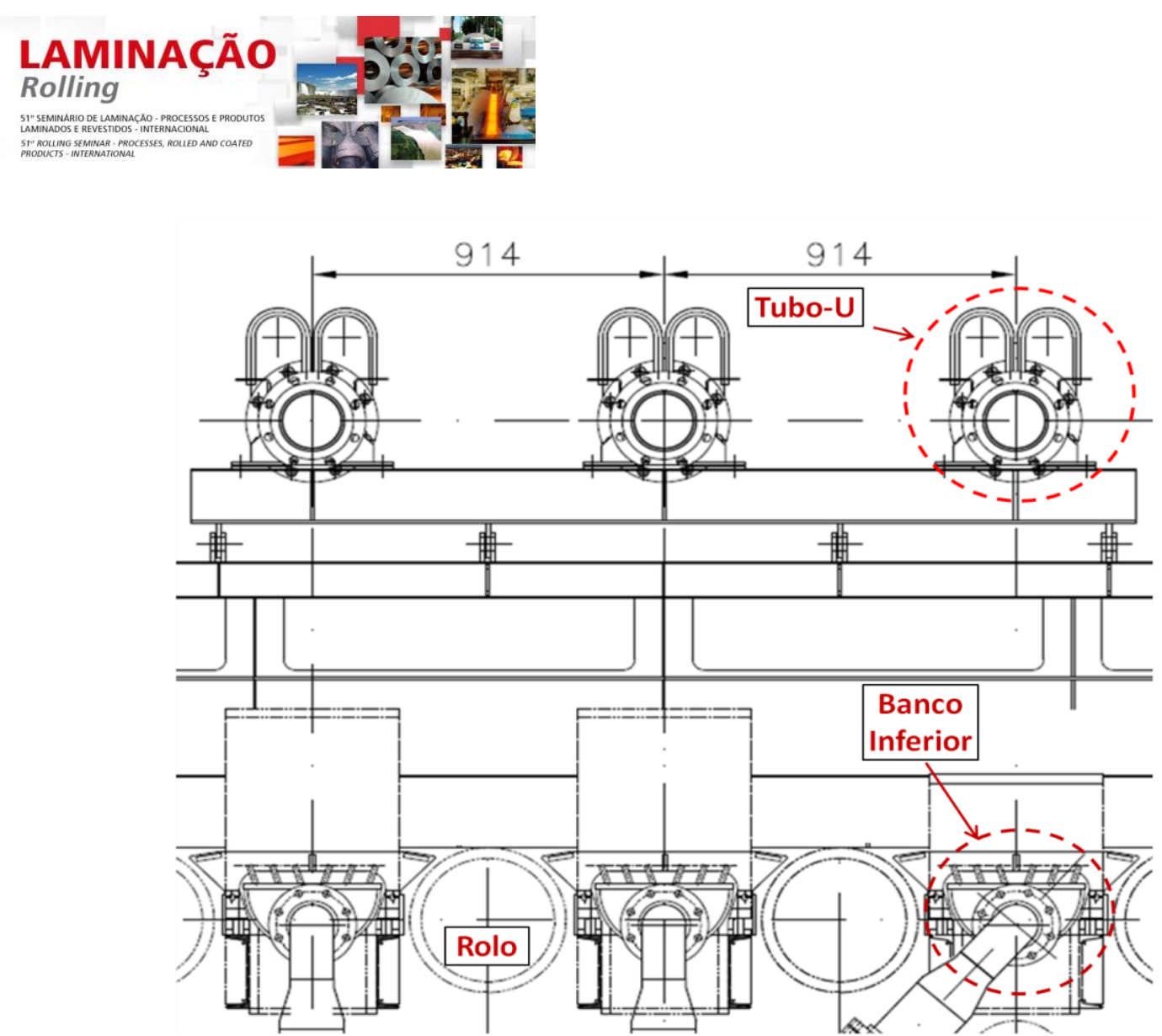

Figura 11. Vista lateral da instalação dos bancos de resfriamento superior e inferior.

$\mathrm{Na}$ Figura 13 são mostradas as curvas de resfriamento resultantes do ensaio com a placa de teste movendo-se a $30 \mathrm{~m} / \mathrm{min}$ e vazão de $200 \mathrm{e} / \mathrm{min}$, com medições de temperatura no interior da placa. Ao passar pelos bancos de resfriamento, observase que a temperatura mais próxima da superfície cai mais rapidamente do que nas demais posições, indicando um perfil de temperatura no interior da placa altamente não-linear, durante este período. A temperatura na posição $1,5 \mathrm{~mm}$ experimenta uma rápida queda de $450^{\circ} \mathrm{C}$. Este valor se mantém constante ao passar pelos dois bancos seguintes. Ao sair de cada zona úmida, a temperatura se recupera. A ausência de água reduz o fluxo de calor e a transferência de calor se dá por radiação e convecção para o ambiente, regime este inferior ao de ebulição[2,5]. $\mathrm{A}$ zona de incidência do jato (zona úmida) é responsável por $90 \%$ do calor transferido no processo de resfriamento de aço por jato d'água incidente [3]. Na superfície superior a recuperação é mais lenta devido à água remanescente e a transferência de calor ocorre em película de vapor. A queda de temperatura na posição $3 \mathrm{~mm}$ é nove vezes menor do que na posição $1,5 \mathrm{~mm}$. A posição $10 \mathrm{~mm}$ está a $1 / 4 \mathrm{da}$ espessura e praticamente não sentiu os efeitos dos picos de temperatura ao passar pelos bancos de resfriamento. Por este motivo esta posição é geralmente escolhida para representar a avaliação da taxa de resfriamento ao longo da espessura.

* Contribuição técnica ao $51^{\circ}$ Seminário de Laminação - Processos e Produtos Laminados e Revestidos, 28 a 31 de outubro de 2014, Foz do Iguaçu, PR, Brasil. 

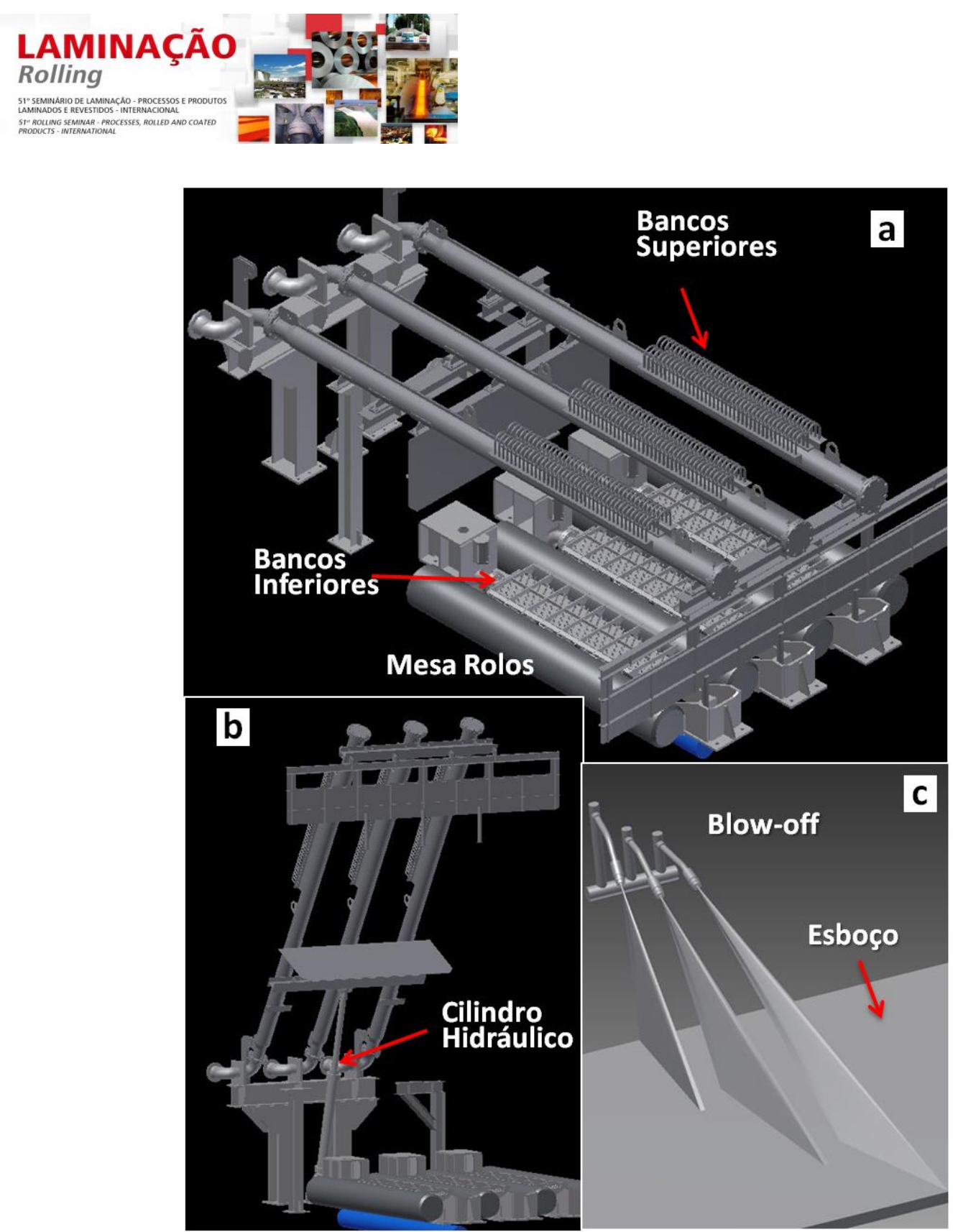

Figura 12. (a) Instalação do sistema de resfriamento na LTQ; (b) Elevação do banco superior para retirada de sucata e manutenção; (c) Sistema de contenção de água por jatos spray.

A Figura 14 mostra as curvas de temperatura e de fluxo de calor na superfície inferior, ambas calculadas a partir das medições realizadas no interior da placa. A temperatura na superfície apresenta uma queda de $710^{\circ} \mathrm{C}$ ao passar pelo primeiro banco de resfriamento, um valor de $260^{\circ} \mathrm{C}$ maior que o medido na posição $1,5 \mathrm{~mm}$ da superfície (ver Figura 13). Diferentemente do que ocorreu na posição 1,5 mm, a queda de temperatura não se mantém constante ao passar pelos demais bancos. Isto se deve ao fato de o pico mínimo se manter quase constante, próximo a $390^{\circ} \mathrm{C}$. O que não ocorreu na posição $1,5 \mathrm{~mm}$, onde o pico mínimo manteve-se caindo ao cruzar os bancos de resfriamento (ver Figura 13). Já os valores dos picos máximos de fluxo de calor, mostrados na Figura 14, são reduzidos após cruzarem cada banco. Isto ocorre pelo fato da temperatura inicial ser menor após cada recuperação, mostrando que o fluxo de calor é fortemente dependente da temperatura superficial. Este resultado está coerente com os resultados encontrados por Leocadio et al. [4]. O pico máximo de fluxo de calor ocorre antes do pico mínimo de temperatura, logo após a água tocar a superfície aquecida, onde ocorre a transição do regime de ebulição em película de vapor para nucleação.

* Contribuição técnica ao $51^{\circ}$ Seminário de Laminação - Processos e Produtos Laminados e Revestidos, 28 a 31 de outubro de 2014, Foz do Iguaçu, PR, Brasil. 

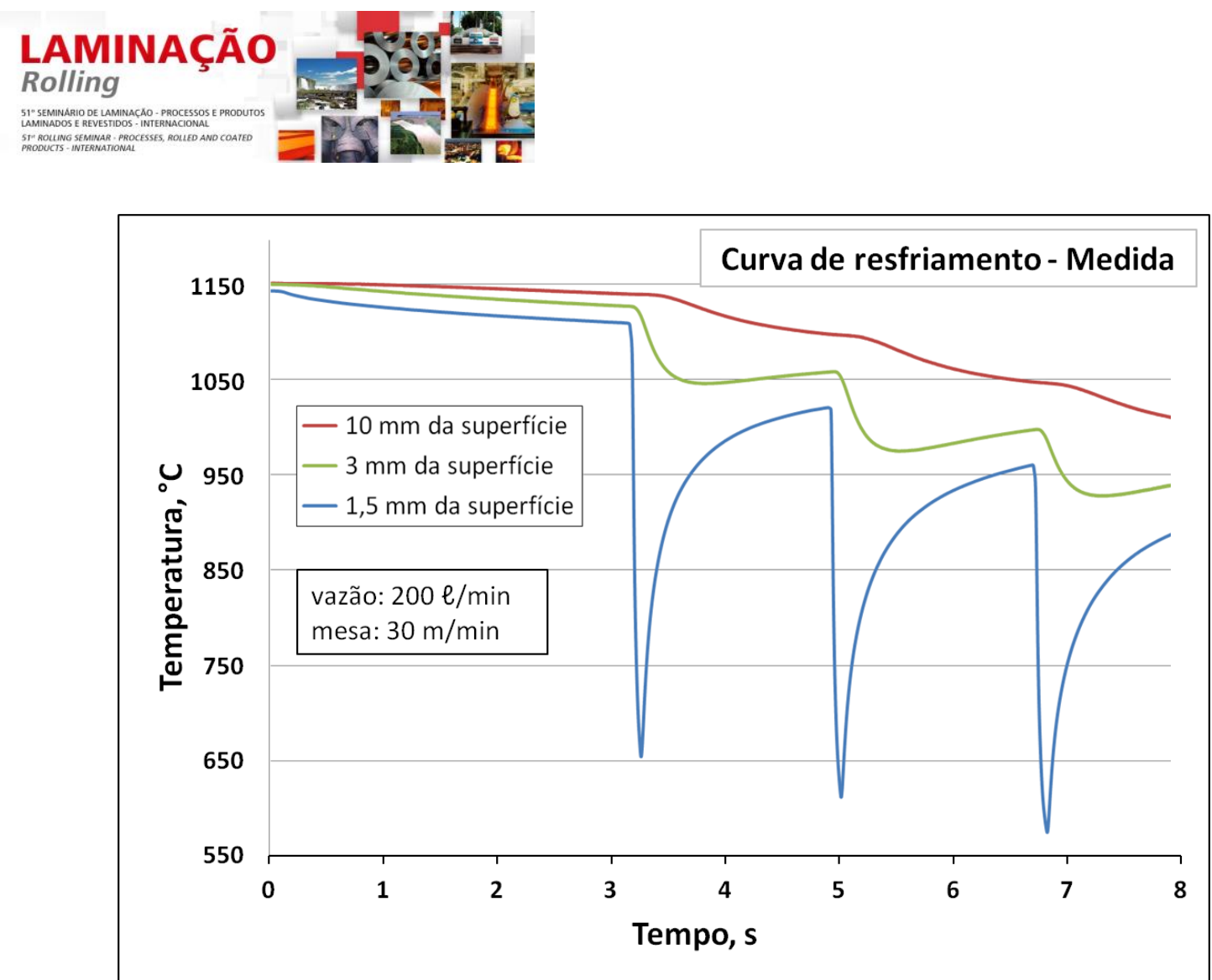

Figura 13. Histórico das temperaturas internas medidas pelos termopares nas profundidades de 1,5, 3 e $10 \mathrm{~mm}$ da superfície inferior da placa.

A partir das curvas de fluxo de calor obtiveram-se as correlações para o cálculo do fluxo de calor na superfície superior (Equação 2) e inferior (Equação 3), para o desenvolvimento do modelo matemático.

$$
\begin{aligned}
& \mathrm{q}_{\mathrm{s}}=238 \cdot\left(\mathrm{T}_{\mathrm{s}}-\mathrm{T}_{\mathrm{sat}}\right)^{1,64} \cdot \mathrm{Q}^{0,545} \\
& \mathrm{q}_{\mathrm{i}}=225 \cdot\left(\mathrm{T}_{\mathrm{s}}-\mathrm{T}_{\mathrm{sat}}\right)^{1,64} \cdot \mathrm{Q}^{0,545}
\end{aligned}
$$

onde $\mathrm{q}_{\mathrm{s}}, \mathrm{q}_{\mathrm{i}}, \mathrm{T}_{\mathrm{s}}, \mathrm{T}_{\text {sat }}$ e $\mathrm{Q}$ representam o fluxo de calor na superfície, em $\mathrm{MW} / \mathrm{m}^{2}$, a temperatura da superfície, em ${ }^{\circ} \mathrm{C}$, a temperatura de saturação da água, em ${ }^{\circ} \mathrm{C}$, e a vazão de água, em $\mathrm{m}^{3} / \mathrm{min}$, respectivamente.

$\mathrm{Na}$ Figura 15 é apresentada a tela principal do modelo de resfriamento desenvolvido. Como dados de entrada tem-se a temperaturas de entrada e de saída do esboço, a velocidade da mesa, espessura e material a ser processado (1). Define-se quais bancos, superiores e inferiores, estarão ligados e suas respectivas vazões de água, bem como o blow-off (3). Como resultados são mostradas as temperaturas calculadas finais, localizadas a $1 / 4$ da espessura superior e inferior (2). $O$ gráfico gerado mostra as curvas de resfriamento a $1 / 4$ da espessura da face superior e inferior (4), bem como a $1 / 8$ da espessura (5). As temperaturas na superfície superior e inferior apresentam picos de queda ao passarem pelos bancos de resfriamento (6) e pelo blow-off (7).

* Contribuição técnica ao $51^{\circ}$ Seminário de Laminação - Processos e Produtos Laminados e Revestidos, 28 a 31 de outubro de 2014, Foz do Iguaçu, PR, Brasil. 


\section{LAMINAÇÃO}

\section{Rolling}

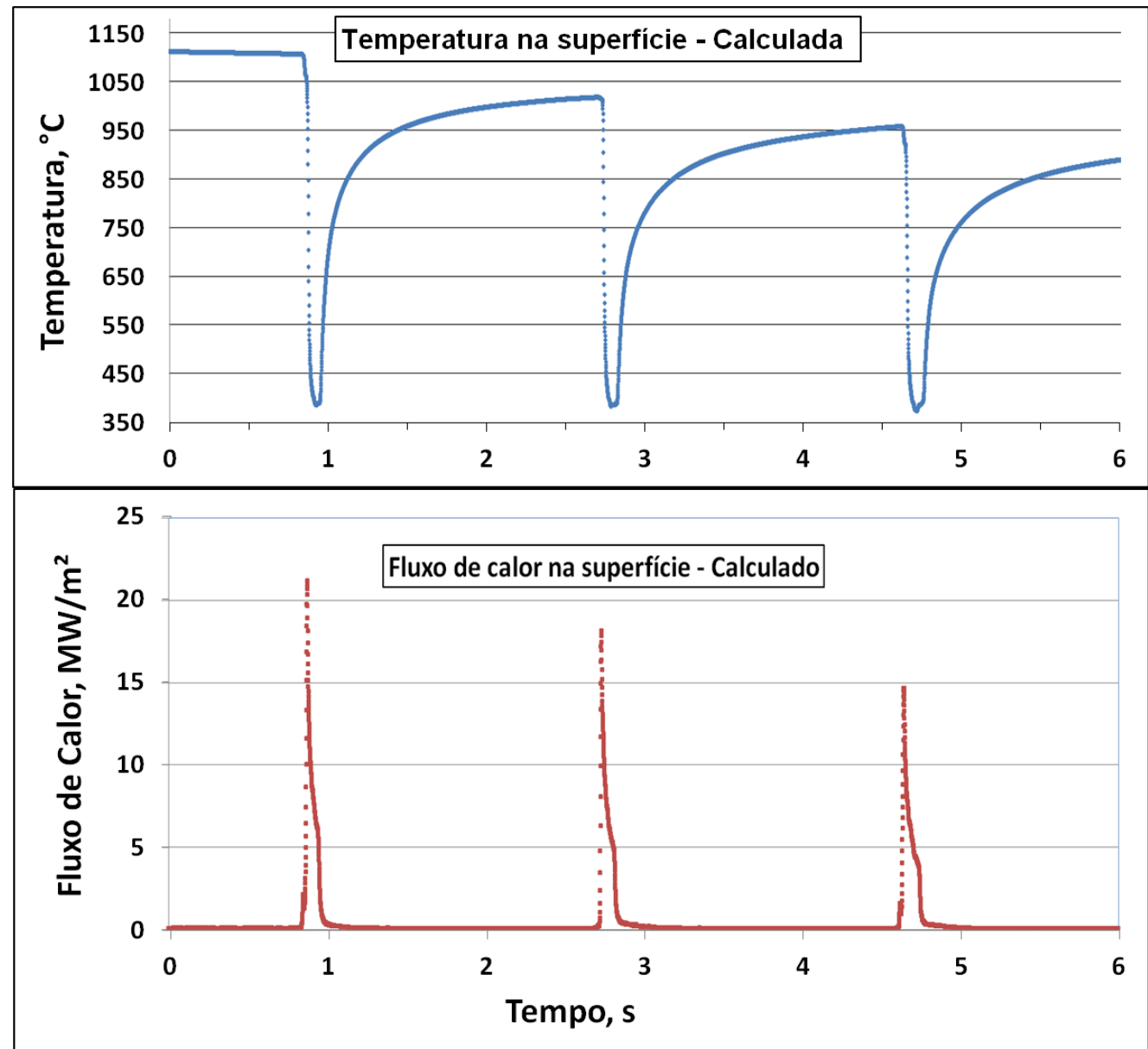

Figura 14. Curvas calculadas de resfriamento e fluxo de calor na superfície.

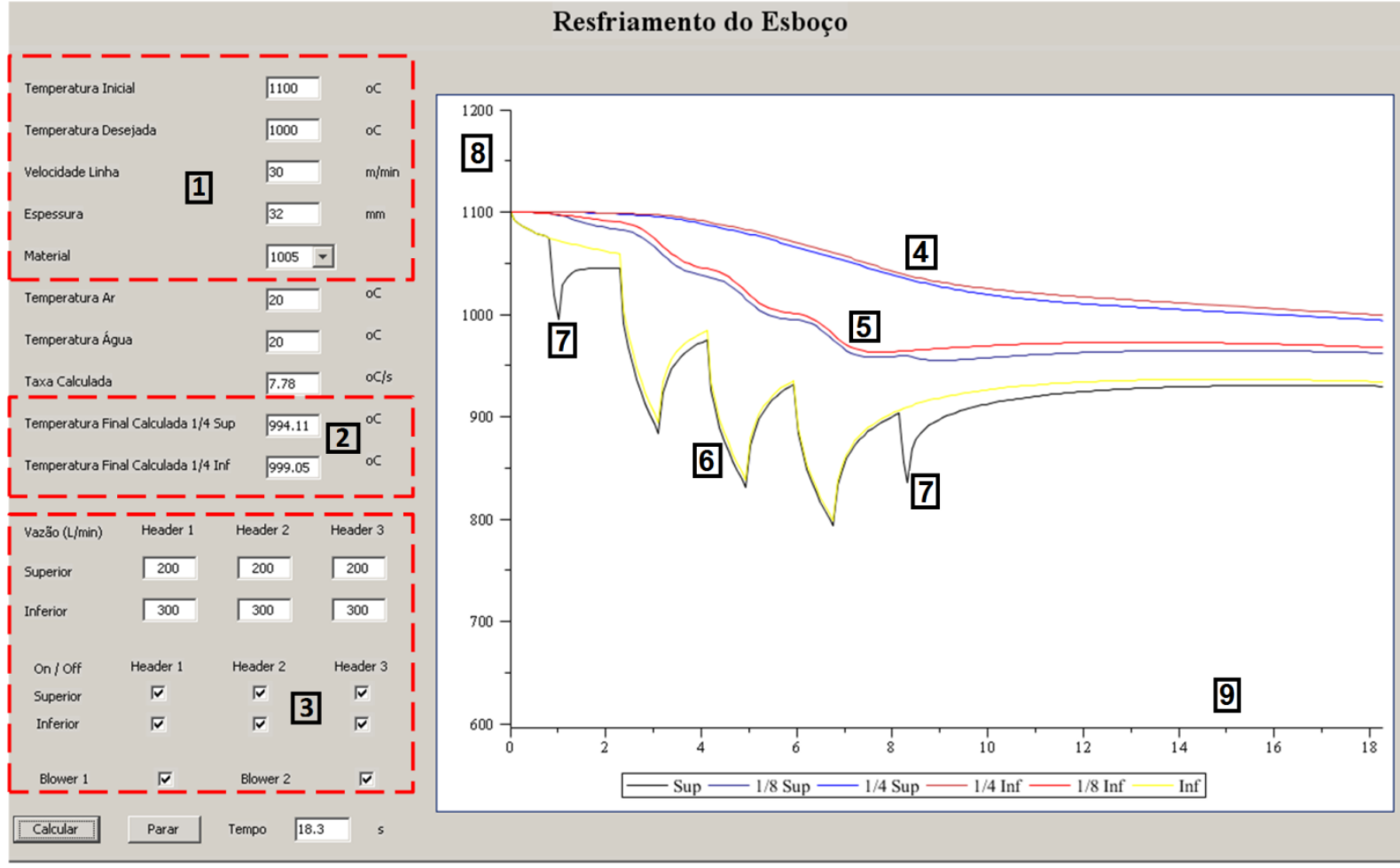

Figura 15. Tela do modelo matemático de resfriamento.

* Contribuição técnica ao $51^{\circ}$ Seminário de Laminação - Processos e Produtos Laminados e Revestidos, 28 a 31 de outubro de 2014, Foz do Iguaçu, PR, Brasil. 


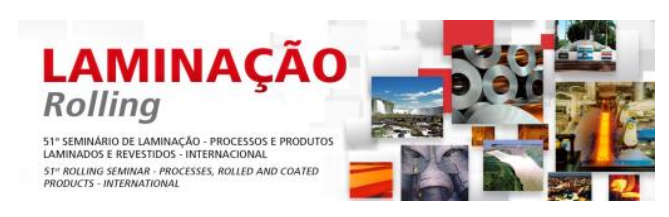

\section{CONCLUSÃO}

O cálculo do comprimento máximo de um jato d'água circular (L) não depende somente de We e Re. O teste de bancada mostrou que o aumento do trecho reto do tubo promove um aumento no comprimento L. Assim, a equação de Sallam et al. [6] deve ser reavaliada e usada com restrição.

Foi desenvolvido o projeto de um sistema de Controle de Temperatura de Esboço (CTE) na Entrada do TA. O sistema é acionado automaticamente, permitindo menor variação da temperatura de entrada no Trem Acabador e promovendo um resfriamento homogêneo em ambas as faces do esboço.

O modelo matemático de resfriamento off-line desenvolvido simula o processo de redução de temperatura do esboço. As condições de contorno levantadas a partir dos testes permitiram introduzir as novas variáveis para o controle do processo industrial.

O modelo prevê que o CTE atenderá aos requisitos de projeto, sendo capaz de reduzir uma temperatura inicial de $1100^{\circ} \mathrm{C}$ para $990^{\circ} \mathrm{C}$ e $1100^{\circ} \mathrm{C}$ para $1020^{\circ} \mathrm{C}$ para um esboço de 30 e $40 \mathrm{~mm}$, respectivamente, ambos a 1/4 da espessura.

Após a implantação do CTE faz-se necessário testes na LTQ para adequação das correlações usadas no modelo matemático de resfriamento.

\section{REFERÊNCIAS}

1 Lee P, Choi H, Lee S. The Effect of Nozzle Height on Cooling Heat Transfer from a Hot Steel Plate by an Impinging Liquid Jet, Iron and Steel Institute of Japan International ISIJ, 2004; 44(4): 704-709.

2 Zumbrunnen DA, Incropera FP, Viskanta R. A method and apparatus for measuring heat transfer distributions on moving and stationary plates cooled by a planar liquid jet, Experimental Thermal and Fluid Science, 1990; 3(2): 202-213.

3 Guo RM. Heat Transfer of Laminar Flow Cooling During Strip Acceleration on Hot Strip Mill Runout Tables, Ironmaking and Steelmaking, p. 49-59, 1993.

4 Leocadio H, Passos J. Heat transfer behavior of a high temperature steel plate cooled by a subcooled impinging circular water jet, $7^{\text {th }} \mathrm{ECI}$ International Conference on Boiling Heat Transfer, pp. 3-7, 2009.

5 Leocadio H, Cabral RM, Gonçalves MM. Resfriamento acelerado piloto, 49 Seminário de Laminação, ABM, 2012.

6 Sallam KA, et al., Liquid breakup at the surface of turbulent round liquid jets in still gases, International Journal of Multiphase Flow, 2002; 28: 427-449.

7 Ochi T, Nakanishi S, Kaji M. Ishigai S. Cooling of a hot plate with an impinging circular water jet, Multi-Phase Flow and Heat transfer III. Part A: Fundamentals, p. 671-681, Elsevier, Amsterdam, 1984.

8 Agrawal C, Kumar R, Gupta A, Chatterjee B, Rewetting and maximum surface heat flux during quenching of hot surface by round water jet impingement, International Journal of Heat and Mass Transfer, 2012; 55: 4772-4782.

9 Trujillo DM, Busby HR. INTEMP - Inverse Heat Transfer Analysis - User's manual, trucomp co., Fountain Valley, CA, 2003, 47 p.

10 Leocadio $\mathrm{H}$. Resfriamento de uma placa de aço à alta temperatura por meio de um jato d'água circular. Dissertação de mestrado em Engenharia Mecânica - Térmica; Florianópolis; Universidade Federal de Santa Catarina, 2008.

\footnotetext{
* Contribuição técnica ao $51^{\circ}$ Seminário de Laminação - Processos e Produtos Laminados e Revestidos, 28 a 31 de outubro de 2014, Foz do Iguaçu, PR, Brasil.
} 